\title{
Factors Influencing MLS Career Choice Amid the COVID-19 Pandemic: A Cross-Sectional Study
}

Lisa Schwartz ( $D$ lschwartz@gwu.edu )

George Washington University https://orcid.org/0000-0003-4981-4948

Cliff Cymrot

The George Washington University

\section{Research article}

Keywords: Career choices, Medical laboratory sciences, Impact of COVID-19, Recruitment, higher education institutions

Posted Date: September 10th, 2020

DOI: https://doi.org/10.21203/rs.3.rs-71466/v1

License: @ (i) This work is licensed under a Creative Commons Attribution 4.0 International License. Read Full License 


\section{Abstract}

Background: The COVID-19 pandemic has had a significant impact on the healthcare workforce. Increased personal risk, job instability, and workplace demands due to COVID-19 may reduce individuals' interests in pursuing a healthcare career. Yet the enhanced visibility of the critical role of healthcare professionals in addressing the crisis may have strengthened individuals' resolve to serve others as a healthcare provider. Moving forward it will be important for higher education institutions to identify what factors may influence prospective students' decisions to pursue a healthcare career, including medical laboratory sciences, so that recruitment efforts may be focused accordingly.

Methods: A cross sectional study was conducted using a modified version of the Health Care Choice instrument to include questions regarding COVID-19. Seventy-two ( $n=72)$ students enrolled in undergraduate and graduate-level medical laboratory science programs at a university in the United States completed the survey. Parametric and non-parametric analyses were performed to identify relationships between factors that influence career choice and particular demographic factors, as well as the impact of COVID-19 on these factors.

Results: Personal interests and nature of the work were the influencing factors rated highest, followed by job prospects. Prior healthcare exposure, self-efficacy, and social influences were rated lower. There were few significant differences based on demographic factors, except those who had military experience. Participants reported being personally impacted by the COVID-19 pandemic, but for most it did not change their career choice.

Conclusions: Medical laboratory sciences students report the factors that influence their career choice are similar to the factors that impact other health professionals in choosing their career. Recruitment strategies should focus on the impact that medical laboratory sciences professionals have on people's lives and the highly skilled, hands-on nature of the work, particularly during and after the COVID-19 pandemic.

\section{Background}

Individuals choose to pursue a career as a health professional for a multitude of reasons, including a desire to help others, job security, intellectual challenge, and prestige [1]. While the factors that may influence these decisions have been previously explored primarily among physicians and nurses, the factors among those who choose to enter the healthcare workforce as medical laboratory scientists (MLS) have not been previously studied. MLS work in a variety of settings, including clinical and research facilities, and their work contributes significantly to the diagnosis, treatment, and monitoring of disease. Demand for MLS is currently high, with the employment growth rate for MLS over the next 10 years estimated to be over 7\% [2]. This highlights the continued MLS workforce shortage, which is a result of a number of factors, including increased retirement rates among laboratory professionals, decreased number of MLS programs graduating students, increased complexity of testing, and a rapidly aging population requiring an increased need for testing [3]. This has culminated in a projected workforce shortage of over 98,000 by the year 2025 [4]. Indeed, there are vacancies of MLS positions across the country in almost every major laboratory department [5]. Further exacerbating the issue is that it takes on average three to six months to fill an MLS position [5]. All of this produces an incredible strain on the current workforce, as health care facility laboratories are forced to have MLS work overtime to compensate for the decreased labor. This shortage has also produced another concerning consequence in that health care facilities are hiring less qualified personnel to perform testing of low to high complexity [5]. It is no wonder that despite there being around 9,100 laboratory professional positions available in the United States, there are currently only 4,900 laboratory professional students graduating each year [6].

To meet this increasing demand, it is critical that higher education institutions (HEI) that train MLS students understand the factors that may influence prospective students' decisions to pursue a career as a MLS so that they may tailor their recruitment efforts to maximize and maintain enrollment. The COVID19 pandemic has placed an enormous strain on the U.S. healthcare system and its workers. According to pathologist Dr. Angela Baldwin, in some instances, MLS are asked to take personal risk and work extended hours to meet the need for increased COVID-19 care and testing [7]. Yet in other cases, hospitals are furloughing MLS due to a steep decline in routine laboratory testing, resulting in the remaining MLS to work in multiple departments in order to keep up with the workload, while having less support from other workers [8]. Therefore, factors that have influenced career choice among MLS may have been impacted by COVID-19.

We hypothesized that a diversity of factors influence MLS students to enter the profession and that these factors have been impacted by the COVID-19 pandemic. Specifically, the research questions were (1) what are the factors that influence career choice among MLS students and recent graduates and (2) what impact has the COVID-19 pandemic had on these factors?

\section{Methods \\ Study aim}

The aim of this study was to identify the factors that influence the career choice among students enrolled in MLS programs and how these factors were impacted at the height of the COVID-19 pandemic in spring and summer 2020.

\section{Study design}

A cross-sectional quantitative study was conducted at The George Washington University in June and July 2020.

\section{Participants}


This study was conducted via a self-administered questionnaire, which was a slightly modified version of the existing Health Care Choice instrument developed by Liaw et al [9], using an online platform, REDCap ${ }^{\mathrm{T}}$. A total of 279 students, undergraduate (92), graduate (18), and post-baccalaureate certificate (169), who were enrolled in the MLS programs at a single university in the United States in the spring or summer 2020 semesters, were recruited.

\section{Data collection}

Following approval by the university's Institutional Review Board, university email addresses of all students were shared with the study investigators by program administrative staff. The study was conducted in summer 2020, at the height of the COVID-19 pandemic, to explore ways that factors that influence the career choices of students concurrently enrolled in an MLS program may have been impacted. An initial email with URL to the study questionnaire in REDCap $^{T M}$ was sent to all potential participants. Follow-up emails were sent to those who had not responded one and two weeks following the initial email. Participants were informed that their participation was voluntary, and no identifying information was collected in the questionnaire to ensure participants' anonymity. The study questionnaire was a slightly modified version of the existing Health Care Choice (HCC) instrument [9], with questions regarding demographics and impact of the COVID-19 pandemic added. A copy of the study instrument is available as Additional file 1. After completion of the questionnaire, participants were directed to a separate, unlinked data entry form, also in REDCap ${ }^{\mathrm{T} M}$, to provide their contact information so that a $\$ 5$ electronic gift card could be sent to them as a token of appreciation for their participation.

\section{Validity and reliability of instrument}

A modified version of the Health Care Choice (HCC) instrument [9] to include questions regarding COVID-19 was used. While the HCC was created with a parallel scale, the Nursing as a Career Choice (NCC) scale, to identify differences between factors that influence choosing a career in nurses and other healthcare professions, only the HCC scale was used in this study, which Liaw et al. [9] noted could be used as a stand-alone scale. All six subscales of the HCC, including 'personal interest', 'prior healthcare exposure', 'self-efficacy', 'job prospects', 'perceived nature of the work', and 'social influences', were included in the questionnaire and rated on a 5-point Likert scale ( $1=$ strongly disagree, 2 = disagree, $3=$ neutral, $4=$ agree, $5=$ strongly agree), with higher scores indicating a more influential career factor and lesser scores indicating a less influential career factor. Psychometric testing of the HCC was reported by Liaw et al. [9]. The Cronbach's alpha of the six subscales of the HCC range from 0.71 to 0.89 , and the correlation coefficients between items and their respective subscales range between 0.39 to 0.78 . The overall Cronbach's alpha for all 35 items of the HCC scale was 0.93 [9]. In addition to the HCC, multiple-choice questions regarding demographic variables were included in the questionnaire, as well as six multiple-choice questions and two open-ended questions asking how the participant and their career choice had been impacted by the COVID-19 pandemic.

\section{Data analysis}

Descriptive statistics were used to analyze the demographic data, while parametric and non-parametric tests were used to analyze relationships between demographic variables and the subscale responses. Significance was set at $<0.05$.

\section{Results \\ Demographics}

A total of 72 out of 279 potential participants responded, representing a $25.8 \%$ response rate. The students who participated were a good representation of the total population of students enrolled in MLS programs in the spring and summer 2020 semesters. The demographic characteristics of the participants are summarized in Table 1. Most were female $(n=56,77.8 \%)$ and Caucasian $(n=39,54.2 \%)$. A significant proportion considered themselves to be a first generation college student $(n=30,41.7 \%)$ and had military experience $(n=14,19.4 \%)$ and/or previous healthcare experience other than in the medical laboratory $(n=32,45.1 \%)$. 
Socio-demographics of participants

\begin{tabular}{|c|c|c|}
\hline Demographics & $N(\%)$ & Program \% \\
\hline \multicolumn{3}{|l|}{ Age (years) } \\
\hline$<30$ & $66.4(50)$ & 58.5 \\
\hline $31-40$ & $22.2(16)$ & 31.1 \\
\hline $41-50$ & $5.6(4)$ & 8.7 \\
\hline$>51$ & $2.8(2)$ & 1.7 \\
\hline \multicolumn{3}{|l|}{ Gender } \\
\hline Male & $15(20.8)$ & 34.8 \\
\hline Female & $56(77.8)$ & 65.2 \\
\hline \multicolumn{3}{|l|}{ Ethnic Group } \\
\hline Caucasian & $39(54.2)$ & 37.3 \\
\hline Latinx & $9(12.5)$ & 14.3 \\
\hline African American & $8(11.1)$ & 21.7 \\
\hline Asian & $9(12.5)$ & 15.2 \\
\hline Mixed & $3(4.2)$ & 3 \\
\hline Other & $2(2.8)$ & 2.9 \\
\hline \multicolumn{3}{|c|}{ First Generation College Student } \\
\hline Yes & $30(41.7)$ & * \\
\hline No & $42(58.3)$ & * \\
\hline \multicolumn{3}{|c|}{ Military Status (current/former) } \\
\hline Yes & $14(19.4)$ & 38.34 \\
\hline No & $58(80.6)$ & 61.66 \\
\hline \multicolumn{3}{|c|}{ Prior Healthcare Experience } \\
\hline 1. Yes & $32(45.1)$ & * \\
\hline 2. No & $39(54.9)$ & * \\
\hline \multicolumn{3}{|l|}{ GPA } \\
\hline$<2.5$ & $1(1.4)$ & \\
\hline $2.5-2.9$ & $9(12.5)$ & 14.5 \\
\hline $3.0-3.4$ & $32(44.4)$ & 49.61 \\
\hline$>3.5$ & $25(34.7)$ & 35.87 \\
\hline \multicolumn{3}{|l|}{ Salary (dollars) } \\
\hline$<24,999$ & $12(16.7)$ & * \\
\hline $25,000-49,999$ & $17(23.6)$ & * \\
\hline $50,000-74,999$ & $18(25.0)$ & * \\
\hline $75,000-99,999$ & $4(5.6)$ & * \\
\hline$>100,000$ & $7(9.7)$ & * \\
\hline
\end{tabular}

\section{Differences between subscales of HCC and demographic variables}

Figure 1 shows the results for each item within each subscale of the HCC. To simplify analysis of these results with specific demographic variables, a subscale minimum, maximum, and mean score was calculated for each subscale. 
Table 2 shows the HCC subscale mean scores differences between specific demographic variables, including gender, first generation status, previous military experience, and prior healthcare experience. One-way ANOVA was performed to compare HCC subscale means based upon age, ethnicity/race, current household income level, and current GPA, the findings of which are reported in Table 3. The findings were synthesized and elaborated for each subscale.

Table 2 Subscale differences for HCC between specific binary demographic variables [Additional file 2]

Table 2

Subscale differences for HCC between specific binary demographic variables

\begin{tabular}{|c|c|c|c|c|c|c|c|c|c|c|c|c|c|c|}
\hline \multirow{3}{*}{ 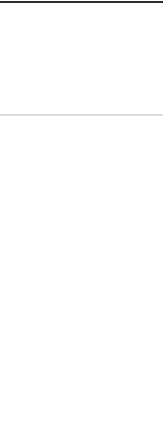 } & \multirow{3}{*}{$\begin{array}{l} \\
\text { Minimum } \\
\& \\
\text { Maximum } \\
\text { score }\end{array}$} & \multirow{3}{*}{$\begin{array}{l}\text { Overall } \\
(\mathrm{N}=72) \\
\text { Mean } \\
(+/- \\
\mathrm{SD})\end{array}$} & \multicolumn{3}{|l|}{ Gender } & \multicolumn{3}{|c|}{ First Generation } & \multicolumn{3}{|c|}{ Military Experience } & \multicolumn{3}{|c|}{$\begin{array}{l}\text { Prior Healthcare } \\
\text { Experience }\end{array}$} \\
\hline & & & $\begin{array}{l}\text { Male } \\
(\mathrm{N}=15)\end{array}$ & $\begin{array}{l}\text { Female } \\
(\mathrm{N}=56)\end{array}$ & $\begin{array}{l}\text { t- } \\
\text { score }\end{array}$ & $\begin{array}{l}\text { Yes } \\
(N=30)\end{array}$ & $\begin{array}{l}\text { No } \\
(\mathrm{N}=42)\end{array}$ & $\begin{array}{l}\text { t- } \\
\text { score }\end{array}$ & $\begin{array}{l}\text { Yes } \\
(\mathrm{N}=14)\end{array}$ & $\begin{array}{l}\text { No } \\
(N=58)\end{array}$ & $\begin{array}{l}\text { t- } \\
\text { score }\end{array}$ & $\begin{array}{l}\text { Yes } \\
(\mathrm{N}=32)\end{array}$ & $\begin{array}{l}\text { No } \\
(\mathrm{N}=39)\end{array}$ & $\begin{array}{l}\text { t- } \\
\text { score }\end{array}$ \\
\hline & & & $\begin{array}{l}\text { Mean } \\
(+/- \\
\text { SD) }\end{array}$ & $\begin{array}{l}\text { Mean } \\
(+/-S D)\end{array}$ & $\begin{array}{l}\mathrm{df} \\
\mathrm{p} \\
\text { value }\end{array}$ & $\begin{array}{l}\text { Mean } \\
(+/- \\
\text { SD) }\end{array}$ & $\begin{array}{l}\text { Mean } \\
(+/- \\
\text { SD) }\end{array}$ & $\begin{array}{l}\mathrm{df} \\
\mathrm{p} \\
\text { value }\end{array}$ & $\begin{array}{l}\text { Mean } \\
(+/- \\
\text { SD) }\end{array}$ & $\begin{array}{l}\text { Mean } \\
(+/- \\
\text { SD) }\end{array}$ & $\begin{array}{l}\text { df } \\
\mathrm{p} \\
\text { value }\end{array}$ & $\begin{array}{l}\text { Mean } \\
(+/- \\
\text { SD) }\end{array}$ & $\begin{array}{l}\text { Mean } \\
(+/- \\
\text { SD) }\end{array}$ & $\begin{array}{l}\text { df } \\
p \\
\text { value }\end{array}$ \\
\hline \multirow{3}{*}{$\begin{array}{l}\text { COVID-19 } \\
\text { changed } \\
\text { desire to } \\
\text { pursue } \\
\text { healthcare } \\
\text { career }\end{array}$} & (5 items) & 3.36 & 3.20 & 3.41 & -.805 & 3.47 & 3.29 & .846 & 3.21 & 3.40 & -.683 & 3.34 & 3.23 & .049 \\
\hline & $1-5$ & $(.893)$ & $(.941)$ & $(.890)$ & 69 & $(0.94)$ & $(0.86)$ & 70 & (.98) & $(.88)$ & 70 & $(.87)$ & $(.90)$ & 70 \\
\hline & & & & & .424 & & & .400 & & & .497 & & & .961 \\
\hline \multirow{3}{*}{$\begin{array}{l}\text { Personal } \\
\text { interest }\end{array}$} & (5 items) & 21.861 & 21.00 & 21.13 & -1.259 & 22.13 & 21.67 & .633 & 20.00 & 22.31 & -2.627 & 21.72 & 21.90 & -.242 \\
\hline & $5-25$ & (3.073) & $(2.00)$ & (3.29) & 69 & $(2.42)$ & $(3.48)$ & 70 & $(5.23)$ & $(2.11)$ & 70 & $(3.80)$ & $(2.37)$ & 69 \\
\hline & & & & & .212 & & & .529 & & & $.011^{\star}$ & & & .809 \\
\hline \multirow{3}{*}{$\begin{array}{l}\text { Prior } \\
\text { healthcare } \\
\text { exposure }\end{array}$} & (6 items) & 14.583 & 15.13 & 14.41 & .507 & 15.00 & 14.29 & .613 & 12.29 & 15.14 & -2.018 & 15.84 & 13.54 & 2.022 \\
\hline & $6-30$ & $(4.849)$ & (4.37) & $(5.03)$ & 69 & $(4.57)$ & $(5.14)$ & 70 & $(6.21)$ & $(4.34)$ & 70 & (5.33) & $(4.27)$ & 69 \\
\hline & & & & & .614 & & & .542 & & & $.047^{\star}$ & & & $.047 *$ \\
\hline \multirow{3}{*}{$\begin{array}{l}\text { Self- } \\
\text { efficacy }\end{array}$} & (4 items) & 15.056 & 15.47 & 15.01 & .542 & 15.63 & 14.64 & 1.462 & 14.29 & 15.24 & -1.125 & 15.06 & 14.92 & .206 \\
\hline & $4-20$ & $(2.858)$ & $(2.50)$ & $(2.93)$ & 69 & $(2.62)$ & $(2.98)$ & 70 & $(4.05)$ & $(2.50)$ & 70 & $(3.02)$ & (2.68) & 69 \\
\hline & & & & & .590 & & & .148 & & & .264 & & & .837 \\
\hline \multirow{3}{*}{$\begin{array}{l}\text { Nature of } \\
\text { the work }\end{array}$} & (5 items) & 20.010 & 20.40 & 20.04 & .352 & 20.90 & 19.52 & 1.659 & 18.21 & 20.55 & -2.301 & 20.22 & 19.90 & .382 \\
\hline & $5-25$ & (3.513) & $(2.90)$ & $(3.71)$ & 69 & $(2.86)$ & $(3.84)$ & 70 & $(4.53)$ & $(3.10)$ & 70 & $(3.91)$ & (3.19) & 69 \\
\hline & & & & & .726 & & & .102 & & & $.024 *$ & & & .704 \\
\hline \multirow{3}{*}{$\begin{array}{l}\text { Job } \\
\text { prospects }\end{array}$} & (7 items) & 26.542 & 25.40 & 26.89 & -1.290 & 27.17 & 26.10 & 1.128 & 24.36 & 27.07 & -2.359 & 26.19 & 26.72 & -.557 \\
\hline & $7-35$ & (3.982) & $(5.14)$ & (3.63) & 69 & $(4.32)$ & (3.71) & 70 & $(4.45)$ & (3.71) & 70 & $(4.80)$ & (3.19) & 69 \\
\hline & & & & & .201 & & & .263 & & & $.021^{\star}$ & & & .579 \\
\hline \multirow{3}{*}{$\begin{array}{l}\text { Social } \\
\text { influences }\end{array}$} & (8 items) & 25.667 & 24.33 & 26.05 & -1.079 & 25.60 & 25.71 & -.087 & 24.71 & 25.90 & -.725 & 26.38 & 24.97 & 1.075 \\
\hline & $8-40$ & $(5.455)$ & $(6.90)$ & $(5.06)$ & 69 & $(5.33)$ & $(6.61)$ & 70 & (5.28) & $(5.12)$ & 70 & (5.49) & (5.44) & 69 \\
\hline & & & & & .284 & & & .931 & & & .471 & & & .286 \\
\hline
\end{tabular}

Significant at ${ }^{*} p<.05$ 
Table 3

Subscale differences for HCC for non-binary demographics

\begin{tabular}{|lllll|}
\hline HCC subscale & Age & Ethnicity/Race & Household Income & GPA \\
\hline Personal interest & $F(4,67)=.570$ & $F(6,65)=.300$ & $F(5,66)=.613$ & $F(4,67)=.051$ \\
& $p=.685$ & $p=.934$ & $p=.690$ & $p=.995$ \\
\hline Prior Health Exposure & $F(4,67)=1.167$ & $F(6,65)=1.030 p=.414$ & $F(5,66)=2.011$ & $F(4,67)=1.432$ \\
& $p=.333$ & & $p=.088$ & $p=.233$ \\
\hline Self-efficacy & $F(4,67)=3.424$ & $F(6,65)=3.383 p=.006^{*}$ & $F(5,66)=.055$ & $F(4,67)=.408$ \\
\hline Perceived nature of the work & $F(4,67)=1.281$ & $F(6,65)=1.719$ & $p=.998$ & $p=.802$ \\
\hline Job prospects & $p=.286$ & $p=.131$ & $F(5,66)=1.422$ & $F(4,67)=.485$ \\
& $F(4,67)=.693$ & $F(6,65)=1.719$ & $p=.228$ & $p=.746$ \\
\hline Social influences & $p=.599$ & $p=.131$ & $F(5,66)=1.309$ & $F(4,67)=.814$ \\
\hline Change in Desire & $F(4,67)=2.617$ & $F(6,65)=2.390$ & $p=.271$ & $p=.521$ \\
\hline & $p=.043^{*}$ & $p=.038^{*}$ & $F(5,66)=1.553$ & $F(4,67)=.672$ \\
\hline * $p<.05$. Subsequent post hoc $c o m p a r i s o n s p e r f o r m e d$ using Tukey HSD described in text. & $p=.186$ & $p=.614$ \\
\hline
\end{tabular}

\section{Personal interest}

The desire to make a difference in someone's life and have a fulfilling career were strong influences on participants' choice to pursue a career in MLS within the 'personal interest' subscale. Not surprisingly, given the nature of the role of MLS in the laboratory with little direct patient contact, the enjoyment of interacting with people was not ranked highly within the 'personal interest' subscale. Having military experience significantly decreased one's 'personal interest', $t(70)=-2.627, p=.011$, but no other significant differences in means of the 'personal interest' subscale were found between other demographic variables (Tables 2 and 3 ).

\section{Prior healthcare exposure}

'Prior exposure to healthcare' was not a strong influencer on MLS career choice. Again, having military experience significantly decreased one's 'personal interest', $t(70)=-2.018, p=.047$, but the influence of 'prior healthcare exposure' was significantly increased among those who had prior healthcare experience, $t(69)=2.022, p=.047$. No other significant differences in means of the 'prior healthcare exposure' subscale were found between other demographic variables (Tables 2 and 3).

\section{Self-efficacy}

'Self-efficacy' did appear to influence MLS career choice but less than 'personal interest'. The vast majority of participants both agree or strongly agree ( $\mathrm{n}=57$, $79.1 \%)$ that the ability to 'make autonomous decisions at work' and both agree or strongly agree $(n=52,72.2 \%)$ that being 'able to make a diagnosis' are important. The mean scores among different age groups differed significantly for 'self-efficacy', $F(4,67)=3.424, p=.013$. Post hoc comparisons using the Tukey HSD test indicated that the mean score for participants less than 30 years of age $(M=16.50$. SD $=2.245)$ was significantly higher than those $41-$ 50 years of age $(M=13.500, S D=.962)$. However, there were no significant differences found between the other age groups. While the overall ANOVA for ethnicity/race was significant for 'self-efficacy', post hoc comparisons using the Tukey HSD found no significant differences between specific ethnicity/race groups.

\section{Nature of the work}

Like 'personal interest', MLS career choice is strongly influenced by the 'nature of the work'. Again given the limited direct patient interaction of MLS, not 'minding to attend to others' hygiene needs' was rated rather low, with $40.3 \%$ noting neutral for this HCC item. The only significant difference found among demographic variables was that those with military experience were significantly less influenced by the 'nature of the work' than those without military experience, $t(70)=-2.301, p=.024$.

\section{Job prospects}

While $41.7 \%(n=30)$ agreed and $51.4 \%(n=37)$ strongly agreed that a career in MLS 'ensures a stable job', other items in this subscale were not rated as highly. Participants with military experience were significantly less influenced by 'job prospects' than those without military experience, $t(70)=-2.359, p=.021$. 'Job prospects' differed significantly by ethnicity/race, $F(6,65)=2.390, p=.038$. Post hoc comparisons using the Tukey HSD test indicated that the mean score for participants that described their ethnicity/race as 'other' $(M=18.00, S D=5.656)$ was significantly less than those who indicated they were Caucasian $(M=$ 
26.769, $S D=3.483)$, Latinx $(M=28.111, S D=3.371)$, or Asian $(M=27.000, S D=3.742)$. There were no significant differences among other demographic variables.

\section{Social influences}

'Social influences' did not appear to have a strong influence on MLS career choice. Of particular note was that the vast majority of participants either strongly disagreed $(n=18,25 \%)$ or disagreed $(n=31,43.1 \%)$ with 'social media has inspired me'. 'Social influences' differed significantly by age group, $F(4,67)=2.617, p$ $=.043$, with those over 51 years of age $(M=14.5, S D=4.950)$ significantly less influenced by 'social influences' than those of all other age groups based on post hoc Tukey HSD tests.

\section{Impact of COVID-19 Pandemic}

Participants were asked whether the COVID-19 pandemic had changed their desire to pursue a healthcare professional career. Select open-ended responses to this question are in Table 4.

Table 4

Open-ended responses regarding impact of COVID-19 on career choice

- Increased my awareness of the importance of my career in MLS.

COVID has not changed my career choice in the slightest. As an experienced paramedic, I have had to deal with many different infectious patients throughout the years and this is just another disease to be aware of.

COVID-19 solidified any misgivings I had had about going back to school; I was finding it hard already to find a job in my degree I also found I had a lot more free time and decided it would be the best time to go back to school. The financial aspect was a bit daunting, given my inability to find a job and then the sudden decline in job postings. However, I was granted financial coverage by a family member who was very supportive of me going back to school for a degree in $M L S$.

More work demand in healthcare, and the general public's perceptions of people in healthcare have shifted in a positive way.

- Covid has made me see how important my career would be and that my job would be secured.

COVID-19 supported my decision to apply for the MLS program. I knew how instrumental the healthcare system would be in the response to COVID-19, and I would like to be a part of the response.

When I signed up, I thought it would be easy to get a job as soon as I'm finished and that I'd be paid well. But now I hear that as the healthcare system delays every treatment that it can, the labs aren't running any of the tests that actually earned them money anymore, and Medicare obliges them to perform COVID-19 tests at a loss. I worry that the labs will have neither the money, nor enough work to hire me after I finish the program.

I had been working as a bartender to pay the bills while in school and I was laid off due to COVID-19. This experience has positively reinforced my choice of a career field that is less sensitive to fluxes in consumer spending.

The pandemic has not swayed my choice of career. There was always going to be risk when working as a lab scientist and I knew going in that I would be working closely with samples from infected patients. However, I also quickly understood that by observing proper precautions the risk of infection is very low, even against something as infectious as the coronavirus.

During the pandemic it has really pushed me mentally and physically. I have been sleeping less and gained weight. It has been the toughest couple of semesters in my entire academic career. Nonetheless, I haven't changed my mind and still want to pursue a career in this field. Actually with the entire pandemic going on it made me want to finish my degree even more and get to work. This is a huge deal and I am happy I will get to be a part of future testing to assist my peers in this field.

I feel even more confident that I chose to go into the right field and wish that I could have started earlier in my life so that I could be out there helping people now.

While the majority reported no change $(n=39,54.2 \%)$, some $(n=6)$ reported that it had decreased their desire significantly $(n=3,4.2 \%)$ or slightly $(n=3,4.2 \%)$, and the remainder $(n=27)$ reported a slight increase $(n=19,26.4 \%)$ or significant increase $(n=8,11.1 \%)$. Chi Square for Independence found no significant differences between these responses and specific binary demographic variables, including gender $\left[X^{2}(8, N=72)=1.765, p>.05\right]$, first generation status $\left[X^{2}(4\right.$, $\mathrm{N}=72)=1.789, p>.05]$, military experience $\left[X^{2}(4, \mathrm{~N}=72)=4.657, p>.05\right]$, or prior healthcare experience $\left[X^{2}(4, \mathrm{~N}=72)=10.850, p>.05\right]$, or other demographic groups (Table 3).

Participants were asked to what degree the COVID-19 pandemic impacted them personally. The tabulated responses are presented in Fig. 2. Select responses to an open-ended question asking "please provide details regarding how your responses to the above questions may have been impacted by COVID-19 (e.g., change in income, decreased/increased work, demand, workplace safety, childcare, care of others like elderly parents or a person with COVID-19)" are presented in Table 5. 
Table 5

Open-ended responses regarding impact of COVID-19 on personal life

\begin{tabular}{|c|c|}
\hline $\begin{array}{l}\text { Personal } \\
\text { Factor }\end{array}$ & Responses \\
\hline \multirow[t]{5}{*}{ Emotionally } & $\begin{array}{l}\text { I was at an emotional downfall when I found out that I was no longer able to say goodbye to a terminally-ill and very close relative. My } \\
\text { relative passed and it was terrible. }\end{array}$ \\
\hline & $\begin{array}{l}\text { COVID-19 has been devastating in terms of childcare, being able to work, study and support my family. In addition to the anxiety and } \\
\text { fears, I have been sad and terribly isolated and helpless during this time. }\end{array}$ \\
\hline & $\begin{array}{l}\text { The current pandemic has taken a toll on my loved ones and I have been trying to be there for everyone emotionally and as physically as } \\
\text { I can while also maintaining safety for everyone involved. I tried to keep all of my answers honest. I am usually very optimistic and I think } \\
\text { some of that was lost as a result of the pandemic. }\end{array}$ \\
\hline & $\begin{array}{l}\text { Increased emotional burden. Increased potential of burnout. Increased depression. Increased stress over raging pandemic, potential to } \\
\text { catch disease, and collapsing economy. }\end{array}$ \\
\hline & - The pandemic is mentally straining on me. It is hard living in NYC with all of this going on and I am on the front lines in my hospital \\
\hline Socially & $\begin{array}{l}\text { I I have struggled with the stress brought on by the pandemic. So much has changed and I can no longer count on the little things being } \\
\text { the same as before to give me a sense of normalcy. Going to the grocery store used to be a de-stresser for me, however now I can't even } \\
\text { guarantee that I will get the food that I need. I suffer from stress headaches every day because of it. Luckily, I am not a very social person, } \\
\text { so I feel as though this pandemic has not affected me in this aspect. }\end{array}$ \\
\hline \multirow[t]{2}{*}{ Physically } & $\begin{array}{l}\text { My partner and I had to make the adjustment in sharing a space } 24 / 7 \text { which had its challenges emotionally. This led to stress eating. } \\
\text { Being physically inactive just added to more weight gain and increased overall stress. Going outside after long periods of being indoors } \\
\text { caused increased headaches and fatigue. I would come home and would immediately want to nap. My grades suffered because I'd spend } \\
\text { more time napping and feeling lethargic that I wouldn't dedicate time to studying. }\end{array}$ \\
\hline & $\begin{array}{l}\text { Fortunately, I maintained my weight but due to the looming uncertainty caused by the pandemic, I found myself having frequent anxiety } \\
\text { attacks. I had headaches almost every other day, I could not focus nor sleep well. }\end{array}$ \\
\hline \multirow[t]{5}{*}{ Financially } & $\begin{array}{l}\text { Right before the pandemic, I had arranged to quit my current job to find a better paying position. Due to the instability and uncertainty of } \\
\text { the pandemic, I had to make the decision to stay on at my current job so there was certain income but my hours were cut to part time. I was } \\
\text { therefore forced to move in with my partner so I could continue to afford rent. }\end{array}$ \\
\hline & - Due to COVID-19, I have not been able to work because I have to take care of my newborn and do not want to risk her getting sick. \\
\hline & - Increased work demand has made me realize that I am not being compensated fairly in comparison to nurses, radiotechs, MRI techs. \\
\hline & - My income did decrease slightly and then increased due to being able to gain employment as a Medical Technician. \\
\hline & $\begin{array}{l}\text { The hospital in which I work had to function on a reduced workload due to the lack of elective surgeries during the pandemic. Due to the } \\
\text { lack of hours, I've had a considerable decrease in income which has made things a bit more difficult. }\end{array}$ \\
\hline
\end{tabular}

Overall participants reported support for their career choice from others, with most reporting strongly disagree or disagree ( $n=51 ; 70.8 \%)$ when asked if a friend and/or family member had questioned their career choice in healthcare during the current pandemic, while 17 (23.7\%) agreed or strongly agreed. Four (5.6\%) responded neutral to this question.

My family has always been concerned for my well-being, even more so during the pandemic. I assured them that I am taking necessary precautions when I'm at work, and when I get home from work. It took awhile for me to maintain my emotions as I do not want to be inflicted with illness nor do i want to pass it on to others. It is hard to think positively initially however I tried not to think about it too much as it worries my family and friends.

Now more than ever I am being questioned about my choice of future career. Pressure from family to be as careful as possible about choosing where to work or find training has also constantly come up. I've been worrying about putting those around me at risk as well.

\section{Discussion}

Although there has been extensive research regarding the factors that influence career choice among students in the health professions, including medicine [10], nursing [11], dentistry [12,13], athletic trainers [14, 15], dieticians [16] and others [17-18], the factors that influence MLS students' career choice have not been previously explored.

Wu et al [19] conducted a systematic review of both quantitative and qualitative studies of motivations for choosing a career in health care, but MLS students were not included. A primary goal of their study was to explore differences between nursing students and other health professionals, given the nursing workforce crisis and the hope of informing potential mitigating recruitment strategies. They found that intrinsic factors, like desire to help others, were consistently found across different health professionals. Similarly, the opportunity to make a difference in someone's life has a strong influence on MLS students' career choice. Wu et al [19] also noted that extrinsic factors, like job security and autonomy, were deemed important to career choice, although salary potential was not a significant influencer for medicine and nursing [19]. Unfortunately, nursing was found to be perceived as a low-paying and low-status job among the public, negatively influencing students from choosing nursing as a career. We found that the nature of the work, including MLS being a challenging, highly skilled occupation requiring hands-on work, were rated highly among MLS students. Although not rated as highly as personal interest and nature of the work, the perception that a career as a MLS offers a stable job with opportunities for career advancement and a high income were also important factors.

Wu et al. [19] found that influences of family and other professionals played a role in career choice among health professionals. However, social influences were not rated highly as influencers on career choice among MLS in our study, although it was dependent upon age, with older respondents rating social 
influence lower than younger respondents. In particular, the majority of respondents strongly disagreed or disagreed that social media had influenced their career choice. It is possible that MLS students did not learn about the career as an option through social media, and thus online social platforms may be areas to consider as an untapped recruitment venue. This is particularly important in an era where social media is pervasive and widely used. By not utilizing social media, MLS programs run the risk of losing out on potential students due to low exposure of the laboratory profession in the public eye. In one study of 469 MLS or MLT (medical laboratory technician) programs, $20 \%$ do not have a program website, and only $40 \%$ of the programs utilized social media, with half indicating using the various platforms once a month for updates [20]. With such a low number of MLS programs utilizing social media, it is no wonder that the results of our study indicated that social media has had little effect on their career choice.

Overall, there were few significant differences in factors that influence career choice among various demographic characteristics. Unlike Wu et al [19] finding significant gender differences in career choice factors among nursing students, we did not note such differences, despite our sample being skewed towards females 2:1. Of note, those respondents with military experience were less influenced by personal interest, prior healthcare exposure, the nature of the work, and job prospects than those without military experience in our study. The MLS programs in this study likely have an oversampling of military students given academic partnerships with the U.S. Armed Services. In addition students serving in the military may have fewer career options to choose from than civilians based on the military's needs. Overall prior exposure to the healthcare system was not a strong influencer of career choice among MLS students studied, yet those students who had already worked in healthcare (i.e., serving as an emergency medical technician) were significantly more likely to rate these factors as having greater influence.

In a follow-up study Wu and colleagues [10] used the HCC and corresponding NCC to identify differences in the two scales among students in medicine, dentistry, pharmacy and social science. When comparing the means of the HCC subscales reported by Wu [10] to those among the MLS students in our study, various similarities and differences emerged, although the significance of the findings was not calculated. As with medicine $(\mathrm{M}=22.70, \mathrm{SD}=2.63)$, dentistry $(M=21.60, S D=2.93)$, pharmacy $(M=20.62, S D=3.25)$ and social science $(M=20.37, S D=3.16)$ students, $M L S$ students $(M=21.861, S D=3.073)$ rated the 'personal interest' subscale high. $M L S$ students $(M=14.583, S D=4.849)$ rated the "prior healthcare exposure' subscale lower than medicine $(M=19.88, S D=$ 4.55), dentistry $(M=19.64, S D=4.49)$, and pharmacy $(M=17.50, S D=4.50)$ students but similarly to social science students $(M=14.78, S D=4.74)$.

'Self-efficacy' was rated higher among MLS $(M=15.056, S D=2.858)$ than medicine $(M=12.93, S D=3.46)$, dentistry $(M=13.43, S D=3.65)$, pharmacy $(M=$ $13.08, S D=2.55)$ and social science $(M=11.19, S D=3.18)$ students. $M L S(M=20.010, S D=3.513)$ rated the 'nature of the work' subscale highly, as did medicine $(M=19.30, S D=3.59)$ and dentistry $(M=20.06, S D=3.31)$ students, but higher than pharmacy $(M=17.90, S D=3.35)$ and social science $(M=15.93$, $\mathrm{SD}=3.35)$ students.

Interestingly, 'job prospects' ranked higher among MLS students $(26.542, S D=3.982)$ than medicine $(M=23.58, S D=5.86)$, dentistry $(M=25.38, S D=4.50)$, pharmacy $(M=24.16, S D=4.95)$ and social science $(M=20.30, S D=5.06)$, which may suggest that MLS students perceive the MLS profession to offer a more stable job. Yet on the other hand, 'social influences' ranked slightly lower among MLS students $(M=25.667, S D=5.455)$ as compared to medicine ( $M=25.99$, $S D=6.37)$, dentistry $(M=26.83, S D=5.94)$, pharmacy $(M=26.17, S D=5.67)$ but not social science students $(M=24.57, S D=5.41)$. Of note, the participants in Wu et al. [10] were much younger than those in our study but distributed similarly by gender. The Wu [10] study was conducted in Singapore, so the majority of participants were Chinese, whereas our study was conducted in the United States and participants were primarily Caucasian. A number of factors that influence career choice among MLS students were significantly impacted by military experience, but this demographic was not reported in Wu's [10] study. It is unclear how these demographic differences may have impacted the subscale comparisons.

Our study was conducted at the height of the COVID-19 pandemic, so the impact of the pandemic on MLS student career choice was also explored. Not unexpectedly, MLS students reported varying degrees to which the COVID-19 pandemic impacted them personally, as summarized in Fig. 2 and Table 5. However, for most students the pandemic did not influence their decision to pursue a career as a MLS. For some the heightened public perception of the value of all healthcare providers, including MLS, reaffirmed that they had chosen the right career path.

More work demand in healthcare, and the general public's perceptions of people in healthcare have shifted in a positive way.

Yet some respondents were discouraged by the limited availability of personal protective equipment (PPE) that plagued the initial response to the healthcare crisis.

Seeing that healthcare workers including laboratorians have not been provided proper PPE has seriously affected my desire to enter the field of MLS. The idea that I would be required by my employer to forego known and/or reasonable safety guidelines and PPE for the patients' diagnosis without respect to my or my family's health (I have an immunocompromised child) is a slap in the face. While I know and accept the risks of being a laboratory scientist, those risks are taken with the understanding that my employer and training will protect me from the worst and known threats that could lead to my death. My family is not encouraged by the treatment of healthcare workers during COVID-19 and have shared their concerns with me also.

In addition, as noted earlier, demand for MLS professionals varied in the early phases of the pandemic, where some had a reduction of hours due to the discontinuation or reduction of elective surgeries and other procedures.

The hospital in which I work had to function on a reduced workload due to the lack of elective surgeries during the pandemic. Due to the lack of hours, I've had a considerable decrease in income which has made things a bit more difficult.

The quote below best encapsulates the impact of the COVID-19 pandemic on MLS students' career choice:

During the pandemic it has really pushed me mentally and physically. I have been sleeping less and gained weight. It has been the toughest couple of semesters in my entire academic career. Nonetheless, I haven't changed my mind and still want to pursue a career in this field. Actually with the entire

Page $9 / 13$ 
pandemic going on it made me want to finish my degree even more and get to work. This is a huge deal and I am happy I will get to be a part of future testing to assist my peers in this field.

\section{Limitations}

While a limitation of the study is its small sample size, and thus reduced statistical power, the results provide insight into the predominant factors influencing MLS as a career choice, as well as the impact COVID-19 has had on these factors. Furthermore, the population surveyed consisted of a diverse range of students including active and retired military, working professionals, various age groups, and from states across the nation, providing a comparable snapshot of the MLS student population from which it was taken, which may allow the results to be applicable to other MLS programs throughout the country.

\section{Conclusions}

The need for qualified MLS to meet the demands of the workforce is a critical issue that will require a number of different solutions. One of the most important ways of meeting this need is to increase the number of graduating MLS students entering the workforce each year. There are a number of different strategies to help meet this need that range from increased retention, academic support, and recruitment strategies. In order to best tailor recruitment techniques, a valuable component is determining prospective student values, beliefs, and perceptions [20,21]. This study is the first to highlight the factors that influence students' decisions to pursue a career as a MLS and therefore can guide recruitment strategies.

Overall, MLS students rate 'personal interest', such as the 'desire to make a difference in someone's life' and 'have a fulfilling career', and the 'nature of the work', requiring high, hands-on skills, high among influencing factors, and are fairly aligned with those of other health profession students [10]. Yet 'social influence', including social media and perceived public image, were not rated as highly. Armed with this knowledge, IHE can develop recruitment strategies, particularly using social media platforms, that focus on the factors that appear to most influence MLS students. Given that the COVID-19 pandemic did not negatively impact, and for some enhanced, MLS students' resolve to be a MLS, personal experiences of MLS professionals who worked during this challenging time may be particularly effective messengers of the benefits, despite inherent risks, of the profession.

\section{List Of Abbreviations}

IHE - institutions of higher education

MLS - medical laboratory scientists

PPE - personal protective equipment

REDCap $^{\mathrm{TM}}$ - Research Electronic Data Capture

\section{Declarations}

\section{Ethics approval and consent to participate}

The study was approved by the George Washington University Institutional Review Board (IRB\# NCR202560). The participants were provided with written information on the purpose of the research study. No written consent was needed: consent was implied by completing the online questionnaire.

\section{Consent for publication}

Not applicable.

\section{Availability of data and materials}

Datasets supporting the conclusions of this article are included within the article. The raw data of individual participants will not be shared due to confidentiality agreements approved by the Institutional Review Board.

\section{Competing interests}

The authors declare that they have no competing interest. LS and CC are faculty members of the university where the study took place.

\section{Funding}

Gift cards provided to study participants were purchased with funds designated for research purposes from The George Washington University Department of Biomedical Laboratory Sciences.

\section{Authors' contributions}

Study design: LS, CC. Data collection: LS,CC. Data analysis: LS,CC. Manuscript writing: LS, CC. Critical revision: LS, CC. All authors read and approved the final version of the manuscript.

\section{Acknowledgements}


We would like to thank the Medical Laboratory Sciences Programs students from The George Washington University for participating in the research study.

\section{References}

1. McLaughlin K, Moutray M, Moore C. Career motivation in nursing students and the perceived influence of significant others. Journal of Advanced Nursing. 2010; doi: 10.1111/j.1365-2648.2009.05147.x

2. U.S. Bureau of Labor Statistics: Clinical Laboratory Technologists and Technicians. Available from: https://www.bls.gov/ooh/healthcare/clinicallaboratory-technologists-and-technicians.htm (2020). Accessed 1 Sep 2020.

3. Freeman J. A Shortage of Skilled Medical Lab Workers Is Looming [Internet]. 2019 [cited 2020Sep2]. Available from: https://blogs.scientificamerican.com/observations/a-shortage-of-skilled-medical-lab-workers-is-looming/

4. Kavilanz P. The US can't keep up with demand for health care workers [Internet]. CNN Money. Cable News Network; 2018 [cited 2020 Sep2]. Available from: https://money.cnn.com/2018/05/04/news/economy/health-care-workers-shortage/index.html

5. Garcia E, Kundu I, Kelly M, Soles R. The American Society for Clinical Pathology's 2018 Vacancy Survey of Medical Laboratories in the United States. American Journal of Clinical Pathology. 2019; https://doi.org/10.1093/ajcp/aqz046

6. Rohde R. Beating Pandemics Like COVID-19 Requires More Medical Laboratory Professionals, This Virologist Explains [Internet]. Forbes. Forbes Magazine; 2020 [cited 2020Sep2]. Available from: https://www.forbes.com/sites/coronavirusfrontlines/2020/04/22/beating-pandemics-like-covid-19requires-more-medical-laboratory-professionals-this-virologist-explains/

7. Baldwin A. Lab workers are unseen warriors fighting the coronavirus [Internet]. ABC News. ABC News Network; 2020 [cited 2020 Sep2]. Available from: https://abcnews.go.com/Health/lab-workers-unseen-warriors-fighting-coronavirus/story?id=69962475

8. Paavola A. 266 hospitals furloughing workers in response to COVID-19: Many U.S. hospitals and health systems have suspended elective procedures to save capacity, supplies and staff to treat COVID-19 patients. [Internet]. Becker's Hospital Review. 2020 [cited 2020Sep2]. Available from: https://www.beckershospitalreview.com/finance/49-hospitals-furloughing-workers-in-response-to-covid-19.html

9. Liaw SY, Wu LT, Lopez V, et al. Development and psychometric testing of an instrument to compare career choice influences and perceptions of nursing among healthcare students. BMC medical education. 2017; doi:10.1186/s12909-017-0910-7

10. Wu LT, Wang W, Holroyd E, Lopez V, Liaw SY. Factors deterring dentistry, medical, pharmacy, and social science undergraduates from pursuing nursing as a healthcare career: a cross-sectional study in an Asian university. BMC Medical Education. 2018. doi: 10.1186/s12909-018-1118-1

11. Lee KJ, Kim M. Occupational values of nurses who succeeded their mothers in nursing. Journal of Advanced Nursing. 2019; doi: 10.1111/jan.13976

12. Butters JM, Winter PA. Professional motivation and career plan differences between African-American and Caucasian dental students: implications for improving workforce diversity. J Natl Med Assoc. 2002;94:492-504.

13. Gallagher, J., Clarke, W. and Wilson, N. (2008), Understanding the motivation: a qualitative study of dental students' choice of professional career. European Journal of Dental Education, 12: 89-98. doi:10.1111/j.1600-0579.2008.00506.x

14. Benes SS, Mazerolle SM. Factors influencing athletic training students' perceptions of the athletic training profession and career choice. Athl Train Educ J. 2014:9(3):104-112.

15. Mensch J, Mitchell M. Choosing a Career in Athletic Training: Exploring the Perceptions of Potential Recruits. Journal of Athletic Training. 2008;doi:10.4085/1062-6050-43.1.70.

16. Suarez VV, Shanklin CW. Evaluating career values of dietetic students. A model for other allied health professions. Journal of Allied Health. 2004 ;33(1):51-54.

17. Brown-West AP. Influencers of career choice among allied health students. Journal of Allied Health. 1991;20(3):181-189.

18. Whitehouse AJO, Hird K, Cocks N. The Recruitment and Retention of Speech and Language Therapists: What Do University Students Find Important? J Allied Health 2007 Fall;36(3):131-6.

19. Wu LT, Low MM, Tan KK, Lopez V, Liaw SY. Why not nursing? A systematic review of factors influencing career choice among healthcare students. Int Nurs Rev. 2015; doi:10.1111/inr.12220

20. Beazer K, Cummins K. Effective Marketing Strategies for a Medical Laboratory Science Program. American Society for Clinical Laboratory Science. 2020; doi: 10.29074 /ascls. 119.002154

21. Coombs C. Improving the Recruitment and Return of Nurses and Allied Health Professionals: A Quantitative Study. Health Services Management Research, 2007; doi:10.1258/095148407779614972.

\section{Figures}




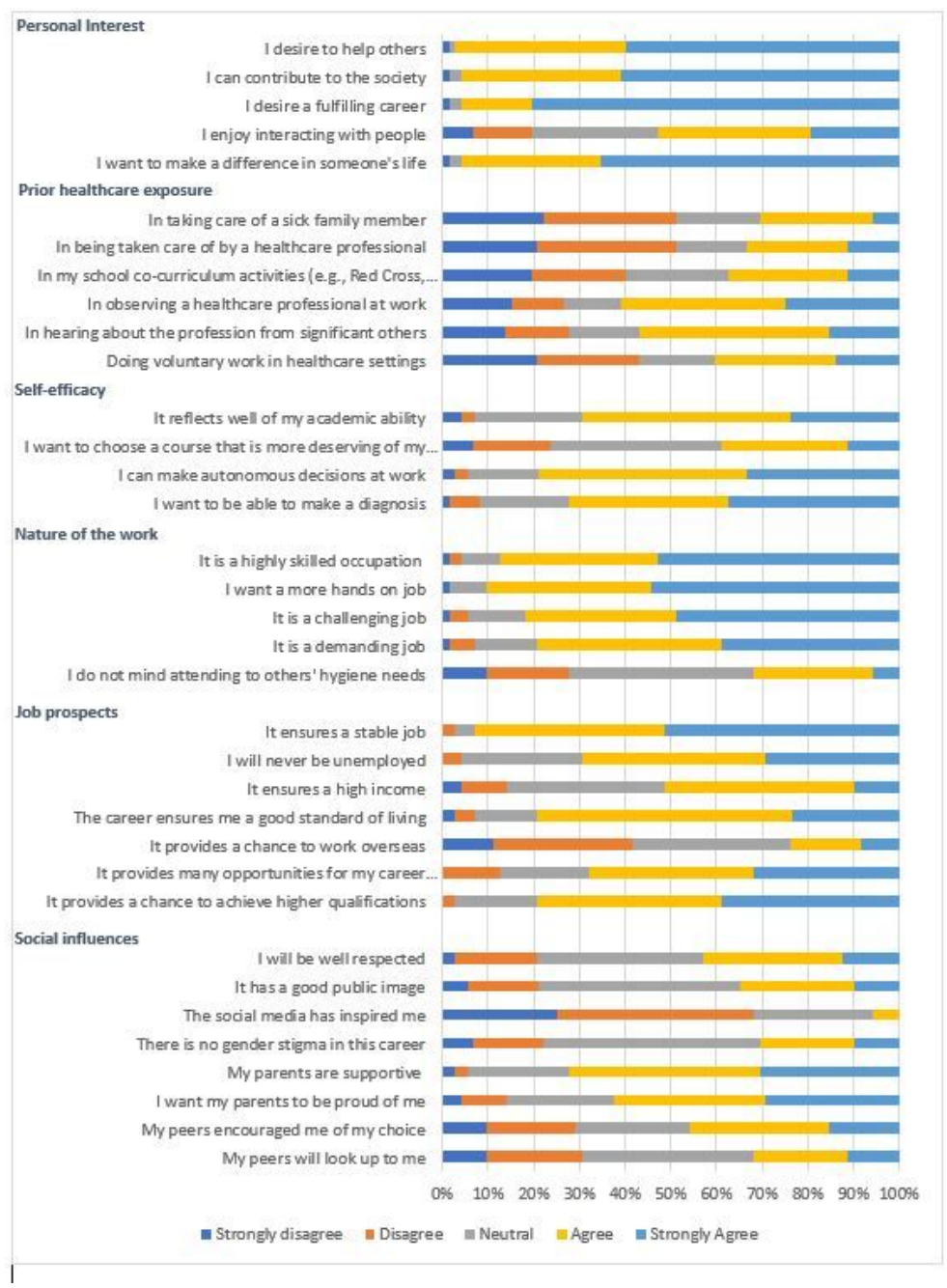

Figure 1

Degree of influence of HCC items on MLS career choice

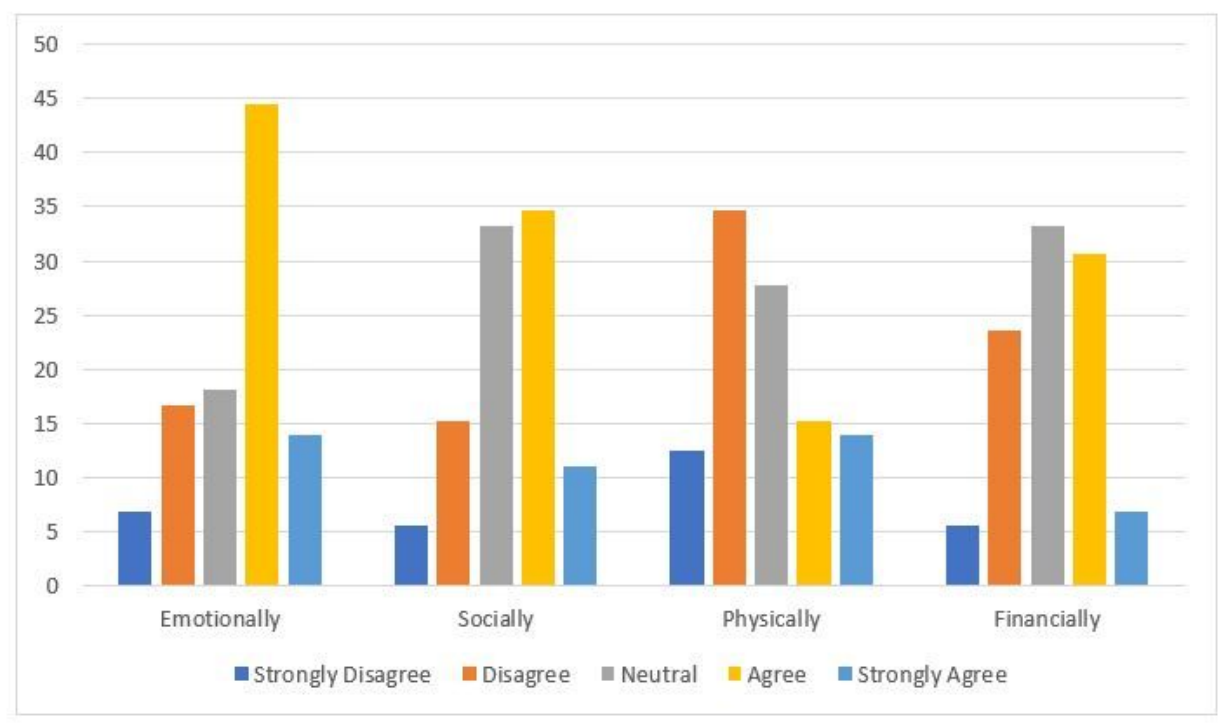

Figure 2

Personal impact of COVID-19 pandemic

\section{Supplementary Files}


This is a list of supplementary files associated with this preprint. Click to download.

- AdditionalFile2.Table2SubscaledifferencesforHCC.docx

- Additionalfile1.MLSCareerChoicesurvey.docx 